\title{
Os sentidos e os efeitos sociais da informação televisiva em saúde: um estudo de recepção com pacientes do câncer de mama
}

\author{
The senses and the social effects of information about health on TV: a \\ reception study with patients of breast cancer
}

\section{Los sentidos y los efectos sociales de la información televisiva sobre salud: un estudio de recepción con pacientes de lo cáncer de mama}

\author{
Allan Gouvêa | allangouvea@yahoo.com.br \\ Universidade Federal de Juiz de Fora, Programa de Pós-graduação em Comunicação. Juiz de Fora, MG, Brasil. \\ Iluska Coutinho|iluskac@uol.com.br \\ Universidade Federal de Juiz de Fora, Programa de Pós-graduação em Comunicação. Juiz de Fora, MG, Brasil.
}

\section{Resumo}

Este artigo resulta de um projeto de pesquisa desenvolvido entre 2012 e 2015 que reuniu uma análise de centenas de produtos midiáticos, entrevistas com profissionais de saúde e pacientes, tendo como foco a cobertura televisiva do câncer. Com a finalidade de sistematizar os sentidos, as impressões e as percepções de um grupo de pacientes (em diferentes fases de tratamento) e ex-pacientes, que foram diagnosticadas com o câncer de mama, a pesquisa teve como intuito principal verificar se os significados produzidos pela mídia televisiva, no âmbito desse tipo de cobertura, correspondem àqueles vivenciados por portadores da doença. Para isso, tomou-se como amostra um grupo de mulheres, constituído em um hospital oncológico do município de Juiz de Fora, MG. e foram utilizadas técnicas de observação não participante e de grupo de discussão.

Palavras-chave: Informação; Câncer; Televisão; Sentidos; Recepção.

\begin{abstract}
This paper results from a research project developed between 2012 and 2015 combining an analysis of hundreds of media products, interviews with health professionals and patients, and the focus on television coverage of cancer. Aiming to systematize the senses, impressions and perceptions of a group of patients (at different stages of treatment) and former patients who were diagnosed with breast cancer, the main purpose of the research was verifying the cancer's meanings produced by the television, in a comparative perspective with cancer's meanings for the patients. We selected as sample a group of women from an oncology hospital in Juiz de Fora, Minas Gerais, and we used techniques of non-participant observation and discussion group.
\end{abstract}

Keywords: Information; Cancer; Television; Senses; Reception. 


\section{Resumen}

Este artículo resulta de un proyecto de investigación desarrollado entre 2012 y 2015, que reúne el análisis de cientos de productos de medios de comunicación, entrevistas con profesionales de la salud y pacientes, centrada en la cobertura televisiva del cáncer. Teniendo como finalidad sistematizar los sentidos, las impresiones y percepciones de un grupo de pacientes (en diferentes etapas de tratamiento) y ex pacientes que fueron diagnosticadas con cáncer de mama, el objetivo principal de la investigación fue verificar la correspondencia entre los significados producidos por los medios televisivos y lo experimentado por las personas afectadas con esta enfermedad. Se tomó como muestra un grupo de mujeres atendidas en un hospital de oncología del municipio de Juiz de Fora, Minas Gerais y se utilizó la técnica de observación no participante y de grupo de discusión.

Palabras clave: Información; Cáncer; TV; Sentido; Recepción.

Contribuição dos autores:

Concepção e desenho do estudo: Allan Gouvêa e Iluska Coutinho.

Aquisição, análise ou interpretação dos dados: Allan Gouvêa e Iluska Coutinho.

Redação do manuscrito: Allan Gouvêa.

Revisão crítica do conteúdo intelectual: Iluska Coutinho.

Declaração de conflito de interesses: Os autores declaram que não há quaisquer conflitos de interesse.

Fontes de financiamentos: Coordenação de Aperfeiçoamento de Pessoal de Nível Superior (Capes).

Agradecimento/Contribuições adicionais: Associação Feminina de Prevenção e Combate ao Câncer de Juiz de Fora (Ascomcer).

Histórico do artigo: Submetido: 11.ago.2015 | Aceito: 05.nov.2015 | Publicado: 31.mar.2016.

Dados abertos: não.

Apresentação anterior: Não.

Licença: CC BY-NC atribuição não comercial. Com essa licença é permitido acessar, baixar (download), copiar, imprimir, compartilhar, reutilizar e distribuir os artigos, desde que para uso não comercial e com a citação da fonte, conferindo os devidos créditos de autoria e menção à Reciis. Nesses casos, nenhuma permissão é necessária por parte dos autores ou dos editores. 


\section{Introdução}

[...] as fantasias punitivas ou sentimentais forjadas em torno dessa situação [de doença]; não a verdadeira geografia, mas os estereótipos do caráter nacional. [...] a maneira mais honesta de encarála - a mais saudável de ficar doente - é aquela que estiver mais depurada de pensamentos metafóricos, que for mais resistente a tais pensamentos. [...] [A] doença [o câncer] é intratável e caprichosa - ou seja, um mal não compreendido - numa era em que a premissa básica da medicina é a de que todas as doenças podem ser curadas. ${ }^{1}$

Não é tão recente a noção de que as neoplasias levantam contra si mesmas os mais diversos sentidos, que deram origem a metáforas e mitos, que colocam a enfermidade como uma espécie de tabu, sujeito a desconhecimentos, temor, preconceitos e dilemas. Essas ideias podem estar relacionadas com a gravidade da doença, ainda que a medicina tenha conquistado grandes avanços no tratamento oncológico e também nas medidas de prevenção.

Dessa maneira, a percepção dos estados de saúde e de doença, na atualidade, está relacionada à forma e ao sentido com que a mídia aborda a temática, uma vez que os meios de comunicação são os principais instrumentos de produção simbólica, e a informação é um dos seus principais atributos, o que vai refletir sobremaneira no comportamento, na opinião e na idiossincrasia de cada indivíduo. Trata-se, assim, de uma relação dupla de consumo e de cidadania, visto que a informação sobre saúde emerge como um produto de interesse da indústria cultural e, concomitantemente, corresponde a dois direitos fundamentais: de comunicação e de saúde.

Em linhas gerais, meios de comunicação atuam na direção de atender às demandas da sociedade e, de algum modo, influenciar a construção de suas necessidades. Porém, subsiste paralelamente uma repercussão no desenvolvimento humano e social, na expectativa da promoção da saúde e da melhoria na qualidade de vida das pessoas. Essas premissas nortearam a execução de uma pesquisa que buscou evidenciar a circularidade dos sentidos na mídia televisiva, que configura um duplo potencial simbólico, por suas representações verbais e imagéticas, sem falar do seu alcance e da sua abrangência. Entendemos que, em alguma medida, a tevê se constitui como um reflexo dos sentidos vigentes em torno da doença, mas que também pode influenciar na (des)mistificação do tema. Por isso, nada mais interessante do que, num segundo momento, tentar mapear ou apreender a percepção dos atores sociais envolvidos nesse tipo de cobertura, visto que esse público é aquele que tem maior interesse no assunto, é o que se vê representado e que precisa ser ouvido. Entende-se que essa técnica de estudos de recepção pode contribuir com o campo interdisciplinar da comunicação e saúde, uma vez que essa estratégia empírica parece ser pouco utilizada, muito embora seja de grande valor para as competências científicas.

Portanto, este artigo objetiva fazer uma síntese das ideias coletadas em pesquisa realizada com um grupo de discussão constituído por mulheres em diferentes fases do tratamento contra o câncer de mama, em janeiro de 2015, em um hospital especializado em oncologia ${ }^{i}$, localizado na cidade de Juiz de Fora, MG. Antes da organização do grupo, a pesquisa envolveu a técnica de observação não participante desse agrupamento, formado pela própria instituição de saúde, que promove encontros semanais das mulheres

O intuito deste artigo é, ainda, problematizar a questão da identidade originada pelas representações midiáticas relacionadas à saúde. Os questionamentos levantados deverão oferecer um panorama das representações sociais do câncer, que envolvem, muitas vezes, o sofrimento humano e a informação que faculta a edificação dos ideais de comunidade e cidadania.

i Associação Feminina de Prevenção e Combate ao Câncer/Hospital Maria José Baeta Reis. 
De acordo com o Instituto Nacional do Câncer (Inca) ${ }^{\mathrm{ii}}$, o câncer de mama é o segundo tipo mais frequente no mundo e mais comum entre as mulheres, respondendo por $22 \%$ dos casos novos a cada ano. Se diagnosticado e tratado oportunamente, o prognóstico é relativamente bom. No Brasil, as taxas de mortalidade por câncer de mama continuam elevadas, muito provavelmente porque a doença ainda é diagnosticada em estágios avançados. De maneira geral, são esperados, para 2015, mais de 570 mil novos casos no país. Os números do Inca indicam a efetiva presença (direta ou indireta) da doença na vida dos brasileiros. Ainda segundo o Instituto, a falta de esclarecimento e de informação são elementos que aumentam a incidência da enfermidade, sobretudo nos países subdesenvolvidos.

\section{Comunicação, informação e saúde}

Para Nilson Moraes, a comunicação na saúde apresenta uma expressão moral ou metáfora narrativa das tragédias modernas que submetem e conduzem o indivíduo a lutar pela sua superação, tendo como prêmio a possibilidade da preservação da saúde e da vida ${ }^{2}$.

Contudo, como o próprio autor sugere, existe uma série de particularidades inerentes aos veículos de comunicação e aos temas de saúde a que se referem. A definição que abre este parágrafo, por exemplo, parece - e aqui se trata de uma hipótese de trabalho - fazer jus à representação das doenças oncológicas no contexto midiático.

A comunicação em saúde pode ser vista, desse modo, muito como um artifício de prevenção, que estaria à cata de estabelecer uma finalidade de munir as pessoas de conhecimento suficiente para que possam evitar a doença, lançando mão de ações que vão ao encontro desse objetivo. Contudo, alguns estudos apontam que nem sempre o ato de informar sobre saúde age nesse sentido. Dione Moura ${ }^{3}$ estabelece dois caminhos da informação relacionada à saúde: (1) aquele que aponta para a ação pós-dano, isto é, que visa "apenas remediar"; e (2) aquele que é anterior ao dano, prevendo a "participação e a prevenção", no âmbito da "comunicação de risco”. O primeiro tópico, de acordo com a professora, não prevê direitos e atende aos interesses da indústria e da publicidade; o segundo poderia ser dividido em três fases da história recente do país: até 1970, um modelo campanhista; a partir da década de 1980, um direito conquistado (saúde e informação); e dos anos 1990 em diante, a etapa da regulamentação, com a estruturação do Sistema Único de Saúde (SUS). ${ }^{\text {iii }}$

Na etapa atual, caracterizada por mais de duas décadas de vigência desse Sistema, parece prevalecer a opinião comum de que há muitas deficiências, de natureza pragmática. Nesse campo, cabem ainda muitas críticas aos processos comunicativos: de todo lado, na saúde, emanam sinais de insatisfação com as atuais práticas comunicativas, seus limites e resultados, quando confrontados com as aspirações e convicções de seus agentes; sinais claros - e muito bem-vindos - de desgaste das perspectivas autoritárias, que não dialogam com essas novas demandas e dinâmicas - e aqui pensamos tanto naquelas empoeiradas, de viés autoritário, quanto naquelas que, igualmente surdas, depositam as expectativas em componentes aparentemente (pós)modernos, em geral tecnológicos. ${ }^{4}$

As autoras Inesita Araújo e Janine Cardoso sugerem, no clássico Comunicação e saúde, que os novos rumos, as novas demandas e os novos desafios desses setores podem ser sistematizados na necessidade de ampliação do acesso às informações governamentais; ampliação do direito de falar e ser ouvido; visibilidade pública para seus temas, interesses e proposições; e mais e melhor acesso às tecnologias da comunicação.

ii [citado 9 ago 2015]. Disponível em: http://www2.inca.gov.br/wps/wcm/connect/tiposdecancer/site/home/mama e http://www. inca.gov.br/estimativa/2014/estimativa-24042014.pdf

iii A implementação do SUS no Brasil é um "divisor de águas" da saúde pública no país, pelo menos em seu projeto ideológico, que prevê, sucintamente, dois tipos de princípios - (a) doutrinários: universalidade, equidade e integralidade; e (b) organizativos: descentralização, hierarquização e participação. 
Por conseguinte, o comparecimento das pautas de saúde na atividade diária do jornalismo envolve uma série de questões que repercutem diretamente na vida dos brasileiros; isso porque, possivelmente, os temas que versam sobre o bem-estar das pessoas potencializam algumas limitações e características comuns do próprio fazer jornalístico. Não é de hoje, por exemplo, a noção de que muitas vezes a imprensa tem interesse particular nas notícias que podem chamar a atenção das pessoas, gerar sensibilização e, até mesmo, comoção do público. Falar de câncer, portanto, pode atingir esse objetivo, por ser ainda uma doença repleta de tabus, mitos, desconhecimentos e preconceitos. É comum ouvir, a título de exemplo, pessoas de mais idade dizendo que, há algum tempo, não se dizia sequer a palavra "câncer", pois talvez houvesse um temor ou uma autocensura consensual. Esse fato pode possibilitar o entendimento, numa perspectiva histórica, do quanto a interdição do tema é prejudicial para que as pessoas lidem com a doença, e essa necessidade se estende aos diferentes atores sociais em cena: pacientes, familiares, amigos, profissionais de saúde etc.

Nesse sentido, a imprensa assume uma função preponderante para desmistificar o assunto; mas, para isso, precisa encontrar uma fórmula, um modo de fazer que dê conta das complexidades inerentes a esse tipo de cobertura. As principais fragilidades, apontadas pela crítica, dizem respeito à ênfase no sensacionalismo ou na dramatização, à superficialidade do conhecimento que evoca, à tensão existente entre jornalistas e especialistas, aos interesses (público e privado) que mobilizam - perspectiva política -, à codificação da linguagem pouco usual, à identidade e à representação, além da narrativa que sustenta ou prejudica a observância desses elementos.

Ao lado das fontes que servem de humanização, há também a necessidade de fazer com que essa abordagem seja sensível, e não dramática ou sensacionalista, com vistas a cumprir um compromisso ético. Desse modo, reside exatamente aqui a importância dos símbolos, dos mitos, dos estereótipos que serão construídos, sustentados ou determinados pelo fazer jornalístico. Um paciente que vê no telejornal uma história de superação do câncer, com uma técnica experimental, pode, por exemplo, ter a esperança de que também conseguirá; o que dificilmente acontecerá em virtude das especificidades da doença, de cada caso e dos recursos disponíveis.

A história da atividade e a pesquisa acadêmica revelam que o jornalismo não se configura, logicamente, como um retrato fidedigno da realidade; mas é, sem dúvida, um fator fundamental na formação do que é essa realidade. A concretude material influencia a mídia, da mesma maneira que a segunda influi na primeira.

Os jornalistas não são simplesmente observadores passivos, mas participantes ativos no processo de construção da realidade. E as notícias não podem ser vistas como emergindo naturalmente dos acontecimentos do mundo real; as notícias acontecem na conjunção de acontecimentos e de textos. Enquanto o acontecimento cria a notícia, a notícia também cria o acontecimento. ${ }^{5}$

Pesquisadores como Goffman ${ }^{6}$ e Berger e Luckmann7 asseveram que a atividade jornalística é, acima de tudo, um elemento ativo e participante na construção da realidade, capaz de estabelecer acontecimentos, reverberar significados e determinar o que a opinião pública deve discutir. Os meios massivos têm, por assim dizer, a possibilidade de construir discursos dos quais a população se vale para compreender o seu próprio mundo. Eles são, portanto, instâncias intermediadoras entre a experiência coletiva e a individual, oferecendo interpretações típicas para problemas definidos como típicos. Tudo o que outras instituições produzem em matéria de interpretações da realidade e de valores, os meios de comunicação selecionam, organizam (empacotam), transformam, na maioria das vezes no curso desse processo, e decidem sobre a forma de sua difusão. ${ }^{8}$

Relacionada com a noção de que os conteúdos jornalísticos oferecem interpretações possíveis (geralmente legitimadoras do senso comum) acerca dos retratos da realidade, ao lidar com as fontes, os repórteres atribuem novos significados aos fatos dos quais as primeiras são testemunhas e de que também já se apropriaram e imprimiram sentidos ao que captaram do assunto. 
Por isso, o jornalista tem como matéria-prima do seu trabalho a construção da realidade social que as fontes de informação criaram. Quando alguém se torna, por exemplo, testemunha de um acontecimento, confere sentido ao que percebe. Constrói, portanto, uma realidade social, objetiva o fenômeno observado. Uma forma de conferir sentido a um fenômeno é quando o contextualizamos [...] o jornalista precisa ir além da construção da realidade social de primeiro grau que a fonte faz. ${ }^{9}$

Dessa forma, parece-nos razoável considerar que notícias e reportagens são produtos de uma realidade construída no interior de um universo simbólico, visto que a linguagem e a narrativa operam sentidos que vão moldar as representações da realidade que é retratada no (tele) jornal. E essas representações são potencializadas no espaço televisivo, por comportarem os símbolos e os sentidos verbais e imagéticos conferidos pelos jornalistas (produtores, repórteres e editores) e pelas fontes de informação - cada qual manifesta as subjetividades no processo de criação dessa realidade mediada.

Nesse debate, cabe ainda a concepção de Hall de que a mídia é "produtora de consentimento" e que o seu poder simbólico é exercido não só pela coerção, mas também pelo consenso, pelo compartilhamento de valores, visões de mundo, conceitos éticos e morais e padrões comportamentais e que, por isso, é essencial estudar os fenômenos socioculturais. A mídia faz parte do campo de forças e disputas pela hegemonia e do processo dialético de produção de consentimento, sendo modelado por eles e influenciando-os ao mesmo tempo. ${ }^{10}$

A audiência da televisão pode ser vista, dessa maneira, como aquela que está agrupada por um laço social, tal como proposto por Dominique Wolton ${ }^{11}$, que estabelece a ideia de que a telinha é o meio pelo qual a população está reunida para se indignar, emocionar, entreter e se informar, simultaneamente.

\section{Olhares e dizeres do câncer em campo}

No âmbito do projeto de pesquisa, a imersão em um espaço reconhecido e marcadamente dedicado ao combate à dor do câncer nos conduziria a importantes noções acerca dos efeitos sociais predominantes no universo que essa doença delimita. Nosso objetivo era buscar reconhecer os sentidos que a informação sobre saúde mobiliza em todos os atores sociais envolvidos, sejam: pacientes (ex em controle ${ }^{\mathrm{iv}}$, em tratamento ou recém-diagnosticados), familiares, amigos, médicos e todos os outros profissionais que lidam com as neoplasias. Outrossim, pretendíamos compreender e descrever a realidade cotidiana do câncer por si mesma, sem a mediação social direta estabelecida pelos meios de comunicação.

Diante dessas necessidades e desses objetivos, precisávamos observar, conhecer e dialogar com esses personagens e, nessa perspectiva, selecionar um espaço no qual fosse possível encontrar todos eles e fomentar essas relações. No município de Juiz de Fora, existem três instituições de destaque na área da oncologia: Instituto Oncológico/Hospital 9 de Julho, Fundação Ricardo Moysés Júnior e Associação Feminina de Prevenção e Combate ao Câncer (Ascomcer)/Hospital Maria José Baeta Reis. A primeira e a última entidades estão habilitadas, pelo Ministério da Saúde, como unidades para procedimentos de Alta Complexidade em Oncologia, além do Hospital Dr. João Felíciov

O Instituto Oncológico é uma organização especializada em câncer, mas é de natureza privada, apesar de possuir convênio com o SUS. A Fundação Ricardo Moysés Júnior dedica-se, especificamente, ao câncer infantil. O Hospital Dr. João Felício engloba outras especialidades médicas. Por essas razões, selecionamos o Hospital Ascomcer, pois, ademais, é uma instituição filantrópica, tradicional na cidade, próximo da

\footnotetext{
iv Após o término do tratamento dos tumores malignos, os pacientes entram na fase denominada de "controle". Esses pacientes comparecem periodicamente ao consultório para realização de exames e outros procedimentos de prevenção, a fim de diminuir as possibilidades de reincidência. Esse período dura, normalmente, cinco anos.

v De acordo com a portaria no 102, de 3 de fevereiro de 2012, do Ministério da Saúde. [citado 24 set 2014]. Disponível em: http://bvsms.saude.gov.br/bvs/saudelegis/sas/2012/prt0102 0302 2012.html
} 
Universidade Federal de Juiz de Fora e cujos atendimentos são realizados, em sua grande maioria, a pacientes do SUS - cerca de 94\%, de acordo com a assessoria de comunicação da entidade.

Apesar de ter em seu nome "Associação Feminina”, o Ascomcer atende pacientes de ambos os sexos, de todas as idades e trata de todos os tipos de neoplasias. A Associação vive de doações e de repasses de recursos pelo poder público, que, também segundo o setor de comunicação, não são suficientes para custear todas as despesas. A Associação mantém e provê o Hospital Maria José Baeta Reis e podem ser considerados uma mesma instituição localizados no mesmo espaço físico e, por isso, conhecidos como Hospital Ascomcer. Por não ter fins lucrativos, a entidade elabora e promove uma série de iniciativas para captação de recursos e doações; há, inclusive, um setor dedicado exclusivamente a esse fim.

Escolhida a instituição, entramos em contato com a sua assessoria de comunicação para apresentar e explicar os objetivos da pesquisa e, por conseguinte, solicitar autorização para realizá-la na entidade. Isso ocorreu em meados de julho de 2014, quando foi a realizada a primeira visita. Fomos recebidos pela assessora Sara Tellado, que pôde conhecer os objetivos do projeto e as atividades propostas para serem realizadas na instituição. Nesse momento, a assessora de comunicação nos conduziu em um tour, para conhecer as instalações do Hospital, e passou uma série de informações institucionais, numa espécie de entrevista não estruturada. Após essa primeira reunião, enviamos um e-mail, com as devidas informações, para que a assessora pudesse solicitar a autorização da diretoria da entidade. Cerca de duas semanas depois, recebemos o retorno positivo e iniciamos, imediatamente, a pesquisa de campo, cujos dados serão parcialmente apresentados a seguir.

Foram aproximadamente seis meses de visitas periódicas, com atividades divididas em três fases: (I) observação não participante e conhecimento da rotina do hospital, além dos projetos implementados; (II) entrevistas semiestruturadas com alguns profissionais, já que foi possível constatar que o câncer demanda um tratamento multiprofissional, incluindo: médicos, enfermeiros, farmacêuticos, fisioterapeutas, nutricionistas, psicólogos, assistentes sociais; e (III) diálogos com as pacientes nas diferentes fases de tratamento. Foram mais de 20 visitas ao hospital, entre os meses de julho de 2014 e janeiro de 2015. Mas, como anunciamos, o objetivo deste artigo é a discussão do último tópico (III) e, por essa razão, apresentamos parte das informações coletadas, especialmente no que tange aos sentidos que são mediados pela tevê.

\section{Prazer, Vitoriosas! - observações preliminares}

O grupo de pacientes que fundamenta nossas reflexões foi o denominado "Grupo Vitoriosas". Constituído apenas por mulheres que tiveram diagnóstico de câncer de mama, o grupo se reúne às quintas-feiras, às 14h3o, e é coordenado por uma psicóloga e uma assistente social. As reuniões também são acompanhadas por estagiários de psicologia, que nem sempre são os mesmos. Ao final de todas as reuniões, as "vitoriosas" fazem exercícios físicos com uma fisioterapeuta.

Antes de iniciarmos as visitas, as profissionais avisaram o grupo sobre nossa presença, e começamos a observar os encontros no dia 21 de agosto de 2014. Nesse dia, havia 12 mulheres. A reunião começa com informações relativas a encontros e compromissos do grupo. As impressões iniciais são as de que se trata de um grupo unido, pessoas com vínculos, laços afetivos firmados que, inclusive, permitem fazer confraternizações dentro e fora do hospital. Elas sempre se organizam em forma de círculo. Muitas conversam ao mesmo tempo, até quando tem alguém falando para todas elas. Em geral, são bem participativas.

Durante a reunião, houve a leitura de um texto ${ }^{\text {vi }}$. A discussão abordou a identificação dessas mulheres com a temática do texto, atribuindo ao lenço um dos símbolos da doença. Uma participante comentou que nem sabia da existência da Ascomcer antes de ter a doença; mas agora "sei de tudo" e fica atenta a tudo que

vi "A convenção mundial dos lenços", extraído da obra Força na peruca! - tragédias \& comédias de um câncer, de Mirela Janotti (Matrix, 2006). 
lembra a doença. Outra contou que, na sua família, os casos de câncer levaram à morte rapidamente, as pessoas sequer chegaram a ficar carecas, por isso ela também não ficaria, imaginava. A psicóloga informa que, em alguns tipos de câncer, a quimioterapia não causa queda de cabelo. Uma mulher afirmou que não é tão ruim ficar sem cabelo, porque cresce rápido. Outra disse que não perdeu todo o cabelo.

Mudando o foco da conversa, uma vitoriosa contou que seu medo foi só das cirurgias de "tirar" e "colocar" (referindo-se, provavelmente, à mastectomia e à cirurgia de reconstrução da mama). Uma delas fez referência a uma matéria do Jornal Nacional, que mostrou que a família toda de uma paciente raspou a cabeça em solidariedade a ela, e ainda doou os fios cortados. Em seguida, falou-se brevemente do projeto "Cabelegria”, que utiliza o Facebook para divulgar suas ações (https://pt-br.facebook.com/cabelegria)

Uma paciente comentou no grupo que não gosta de se olhar no espelho nem que os outros a vejam, porque tirou um quadrante muito grande do seio. Sobre a cirurgia de reconstrução, elas apontam que existem diversos problemas, como falta de pessoal (que é mal remunerado) e de materiais (bisturi, esparadrapo...). Uma delas recomenda fazer repouso com rigor, para evitar problemas posteriores. Além disso, segundo as "Vitoriosas", é preciso aproveitar as oportunidades, porque só tem uma equipe do SUS que faz essa cirurgia na cidade.

Esse primeiro encontro já demonstrou que, de fato, existe um problema de autoestima intrinsecamente relacionado ao câncer de mama. Consequências da queda de cabelo e da retirada da mama são símbolos de feminilidade e, portanto, geram transtornos de ordem emocional. Contudo, a queda de cabelo, ao contrário do que esperávamos, não necessariamente representa uma grande dificuldade para elas, que parecem lidar bem com isso; em virtude do uso de lenços, perucas e porque a calvície é temporária. De todo modo, notamos que esses símbolos materiais são fatores de identificação dessas mulheres, que parecem ter um desejo de comungar experiências e fortalecer vínculos entre si. A vocalização dos problemas do setor de saúde no município é feita em tom de alerta, como quem quer recomendar algo ao outro por experiência própria, como acontece com a recomendação do repouso absoluto. Importante observar as referências informativas presentes, na leitura do livro, na reportagem mencionada e nas redes sociais.

A segunda visita ocorreu no dia 18 de setembro de 2014, quando estavam presentes 20 participantes. Foi um dia dedicado a informações dadas pela nutricionista. Nesse dia, a assistente social transmitiu um pedido do setor de comunicação para participação em um programa de TV, o Bem-estar. Algumas demonstraram interesse. Uma delas afirmou que já deu entrevistas na televisão e que acha importante para mostrar que "o câncer não tem só coisa ruim”. O grupo começava a se preparar para a campanha do "Outubro Rosa", elas estavam adquirindo, por exemplo, tênis rosa para participarem de uma tradicional corrida realizada pelo hospital nessa época.

Para além dos vínculos afetivos construídos, que estabelecem uma comunidade com relações fortes de identidade, as mulheres também parecem sentir orgulho de suas histórias e da situação em que se encontram; por terem "vencido" a doença ou por estarem se saindo bem em relação a esse objetivo. Cada passo no tratamento é visto como uma vitória, sobretudo quando os resultados dos temidos exames se mostram promissores. Foi bem sintomático o depoimento da participante que carrega implícita a noção de que o câncer é comumente abordado na mídia como uma doença de "coisas ruins"; sua ideia é, portanto, dar visibilidade a "coisas boas" que a doença traz.

Nosso terceiro contato data de 25 de setembro de 2014. Houve a apresentação de uma participante novata, que fez mastectomia há nove anos e, por conta de um linfoedema ${ }^{\text {vii }}$, retornou ao hospital e resolveu conhecer o grupo. As demais participantes logo deram informações sobre dois projetos do município que oferecem ginástica, hidroginástica e outros tipos de exercícios para pacientes com câncer de mama.

A assistente social propôs que aquele fosse um “dia para falar". Para a profissional, elas estavam falando muito nas reuniões anteriores e por isso teve a ideia de deixá-las se expressarem livremente. Cada uma

vii O linfoedema ocorre quando um fluido corporal, conhecido como linfa, se acumula nos tecidos moles do corpo, habitualmente num braço ou numa perna. Extraído de: http://www.cirurgia-vascular.pt/linfedema Acesso em 10 ago. 2015. 
tinha a oportunidade de falar sobre o que quisesse, sobre projetos de que participam, relações familiares, entre outros. As informações sobre os projetos despertaram muito interesse e, então, a assistente ficou de pesquisar mais a respeito, sobretudo em relação às vagas disponíveis. Uma das meninas falou, novamente, sobre a importância de mostrar como é o câncer, porque "existem coisas boas".

O olhar das mulheres desse grupo se volta, frequentemente, para enxergar os fatores possibilitados pela doença, que são sempre relacionados ao amadurecimento pessoal e a uma espécie de autoconhecimento. Elas têm uma grande necessidade de mostrar que, apesar das dificuldades, o câncer não é algo tão tenebroso quanto se imagina e, por isso, querem ser um exemplo vivo disso.

A última visita, em caráter de observação, se deu no dia 2 de outubro de 2014, quando estavam presentes 23 participantes e quando a psicóloga retornou das férias. Em função do "Outubro Rosa", a equipe de reportagem da afiliada da Rede Globo em Juiz de Fora - a TV Integração - estava presente nesse dia.

A cobertura era para o programa Bem-estar, de abrangência nacional. Notamos grande mobilização das participantes, que se preparavam (inclusive esteticamente) para as filmagens e as entrevistas. Outro convite foi feito pela assessora de comunicação da Ascomcer, para um evento no dia seguinte, que também seria coberto pela imprensa, que estava procurando duas fontes. Seria realizado um desfile de lenços na ocasião.

A cobertura feita pela equipe deixou evidente a total construção narrativa da história da "Helô", uma participante do grupo, que desde cedo ( $8 \mathrm{~h}$ da manhã) estava dando entrevista para a equipe. A entrada dela no auditório foi totalmente simulada e ela cumprimentou todas as participantes. Tudo sob as lentes da câmera. A personagem do dia, Helô, é considerada como uma referência para as demais, e então ela afirma que é preciso ter "autoelogio", "autoestima" e "autoaceitação". Em outros encontros, não se percebeu essa referência, talvez fosse algo mais implícito da relação delas e que agora emergiu com a reportagem. Uma paciente não quis aparecer no vídeo e, por isso, ficou do lado de fora da sala quando a gravação começou.

Na reunião desse dia, as “meninas" fizeram uma avaliação positiva do encontro da semana anterior, no qual tinham falado à vontade. Mais uma vez, deram notícias de outras participantes. Houve a continuação da leitura do livro Força na peruca!, com o texto "Na balada". A psicóloga explica que o livro é um relato autobiográfico de uma ex-paciente, que gera comicidade e identificação com as histórias, que, regra geral, têm um happy end.

Nesse mesmo dia, algumas relataram o abandono do marido em função da doença e disseram que haviam compreendido a dificuldade deles. Elas questionam se existem ou não estatísticas sobre isso, mas ninguém soube informar. "O problema é nosso", emocionou-se uma participante. Outros casos de maridos foram contados, a exemplo de um que fugiu por não suportar ver a mulher sofrer; outro foi se afastando aos poucos e isso, para a paciente, dificultou muito o tratamento, porque a separação foi um dos momentos mais difíceis para ela, além da queda do cabelo. Cogitou-se a possibilidade de os maridos participarem de algum encontro do grupo viii.

Relatou-se o fato de que o câncer motivou o olhar para si mesmo. Comentou uma 'vitoriosa': "as pessoas mudam após o câncer". Uma também contou que, na sua cidade, as pessoas não pronunciam a palavra "câncer", referem-se a ele como "aquela doença ruim”. E ela questiona: “e existe doença boa?”. Por conta de sua superação, ela se tornou uma referência na cidade. A psicóloga defendeu a ideia de que as campanhas e o ato de dar visibilidade às pessoas que passaram pela doença ajudam na conscientização de outras mulheres. Portanto, para ela, não se deve esconder o câncer.

\section{Sobre as entrevistas dadas para a TV}

As perguntas da jornalista foram muito superficiais, tinham o objetivo de explorar a emoção das pacientes e despertar o sentimento de esperança. Quando perguntadas pela jornalista sobre o significado daquele grupo, elas falaram de "amizade" e "segunda família”. Ao receberem o diagnóstico, elas dizem que é

viii Isso, de fato, ocorreu posteriormente, como contou a assistente social, em entrevista para o projeto. 
como se "abrisse um buraco". E o nome do grupo, em resposta à repórter, é porque a superação é a "vitória" delas, "nós vencemos"- "porque lá no fundo, talvez, eu não acreditasse nessa vitória" $(\mathrm{H}, 2014)$.

As participantes Maria do Carmo e Helô (a primeira foi indicada pela segunda) foram as duas mais entrevistadas. Elas abordaram, acima de tudo, as dificuldades do câncer que as inspiram, além do carinho, da "palavra amiga" por ocasião das cirurgias, que teriam marcado a amizade delas. Ambas se emocionam ao final. Maria do Carmo contou, com muita felicidade, que os nódulos encontrados no outro seio são benignos: "mais uma vitória" (MC, 2014), contou aliviada. As demais participantes também se emocionaram com os depoimentos das duas. "Nós vencemos todos os dias uma batalha após a outra" (H, 2014).

Para a abordagem televisiva, mostra-se que os acessórios e os objetos de Helô, agora, são todos rosados: "o mundo pode ser rosa. Basta você fazer ele ser rosa". As colegas estariam aderindo à cor, "por fora e por dentro". O rosa, para a vitoriosa, simboliza o seu desprendimento, a sua alegria e a sua verdade. A respeito da atuação da repórter, é possível verificar que houve ampla instrução sobre como as participantes deveriam se comportar. Por vezes, até sobre o que e como dizer. Percebemos, na prática, a intensa e a exclusiva exploração das histórias das personagens. A câmera captou todas as ações construídas - um acontecimento preparado para ser midiatizado.

O contato com as pacientes evidenciou, assim, a importância das oportunidades que ela têm de serem ouvidas; tanto entre aqueles que dividem com elas as situações cotidianas, quanto no espaço que possibilita uma visibilidade maior, a exemplo da televisão. A vitória de que elas tanto se orgulham, aparentemente, poderia estimular outras pessoas na mesma situação e, ademais, estimular uma modificação na forma como as pessoas veem a doença na sociedade. Por isso, para obter um depoimento mais preciso, objetivo e direto, foi realizado um grupo de discussão com as vitoriosas, cuja experiência é relatada a seguir.

\section{A visão dos pacientes oncológicos}

Com o intuito de registrar e analisar as impressões das pacientes, escolhemos as participantes do Grupo Vitoriosas para participarem de uma discussão das questões propostas nesse projeto. A reunião ocorreu no dia 22 de janeiro de 2015, às 14h30, no auditório da Ascomcer. Nesse dia, compareceram ao grupo oito mulheres, além de outras duas que chegaram atrasadas e não participaram do debate, possivelmente porque desconheciam o objetivo e a dinâmica. Na semana anterior, contudo, elas já haviam sido informadas sobre o trabalho do grupo de discussão, mas nem todas se lembravam ou estavam sabendo. De acordo com as profissionais, esse reduzido número se deve ao período de férias; todavia, entendemos que se trata de uma quantidade razoável, em exata medida, para problematizar a temática da informação sobre o câncer com a profundidade de que ela carece.

Um pesquisador atuou como moderador do grupo, a fim de orientar as discussões e propor as temáticas. Por isso, para perceber outras expressões comunicativas, convidamos três jornalistas e mestrandas para participarem como observadoras, e uma delas ficou responsável por fazer anotações que facilitassem a identificação das falas das participantes. Allana Meirelles, Nara Salles e Roberta Braga ficaram dispostas em lugares estratégicos dentro do auditório, a fim de que pudessem perceber e visualizar todas as "vitoriosas", além das duas profissionais que coordenam seu grupo. Iniciamos a conversa com as devidas apresentações e informações sobre o projeto e, em seguida, pedimos que cada uma se apresentasse também. Mantendo o sigilo da identidade das participantes, o grupo de discussão ficou constituído como mostra a Tabela 1. 
Tabela 1- Perfil dos participantes dos grupos focais

\begin{tabular}{|c|l|c|}
\hline Participante & Profissão & $\begin{array}{l}\text { Primeiro } \\
\text { diagnóstico em }\end{array}$ \\
\hline V1 & Aposentada & 2008 \\
\hline V2 & $\begin{array}{l}\text { Antes manicure, agora acompanhante de idosas (filha presente na } \\
\text { reunião, ao seu lado) }\end{array}$ & 2009 \\
\hline V3 & Doméstica & 2003 \\
\hline V4 & Atleta (está com câncer pela 3a vez) & 2012 \\
\hline V5 & Aposentada & 2009 \\
\hline V6 & Aposentada & 2008 \\
\hline V7 & Aposentada & 2007 \\
\hline V8 & Aposentada & 2010 \\
\hline
\end{tabular}

Fonte: Elaborada pelos autores deste artigo.

As impressões que tanto relatamos durante o período de observação não participante persistiram durante a realização das reuniões desse grupo; isso, inclusive, foi relatado pelas observadoras. O Grupo Vitoriosas é constituído por mulheres que, em alguma medida, compartilham experiências comuns e isso fortalece os laços entre elas, criando vínculos de amizade. Durante uma hora de conversa, foi possível verificar todas as emoções, entre sorrisos e lágrimas, risadas e tensões. Quando uma fala, ordinariamente as demais fazem gestos de concordância, comovem-se com os depoimentos umas das outras, riem, fazem piadas, emocionam-se, ficam tristes e, invariavelmente, falam simultaneamente, interrompem a fala da outra e às vezes discutem, ao discordarem em determinado aspecto ${ }^{\text {ix }}$. Como muitas delas comentam, parecem, de fato, uma família. Registramos apenas uma intervenção da participante $V_{7}$ e nenhum depoimento das vitoriosas V3 e V5 (bem como das outras duas que chegaram muito atrasadas e não foram identificadas).

A reunião começou com o tema 'diagnóstico', sobre como elas reagiram ao receber a notícia de que estavam com câncer de mama. De uma maneira geral, elas afirmam que o primeiro diagnóstico não assusta tanto quanto o segundo (ou quando identificam alguma nodulação suspeita de ser um novo tumor). Essa é a visão das participantes V4, V6 e V7; a segunda chega a contar que teve um tumor benigno seis anos depois do diagnóstico de câncer e então, para ela, "a gente leva um baque, entra meio em pânico. Talvez porque quando você recebe a notícia pela primeira vez, você não sabe pelo que vai passar. Você ainda não entrou na quimio, não entrou na rádio; mas depois que você entra numa quimio, aí você começa a ter medo de voltar" (V6, 2015). Para elas, o medo vem pelo conhecimento das consequências, e não pelo desconhecimento, como se poderia imaginar.

Alguns depoimentos dão indícios da realidade dos pacientes com câncer, que sofrem pela doença em si e pelo desconhecimento da população, que não sabe lidar com a doença, menos ainda com os pacientes. Isso é fruto, muito provavelmente, das interdições do tema de uma maneira geral. Em alguma medida, em espaços mais públicos, os pacientes se veem marginalizados ou excluídos, em função do tratamento que lhe é oferecido e de atitudes que demonstram discriminação e preconceito. Por conta disso, a vitoriosa V1 defende que o câncer ainda é um grande tabu, mas que, ao ser mais divulgado, as ideias a seu respeito têm se modificado. Por isso, ela acredita que é preciso falar abertamente, como acontece no grupo. Ela nota que as novatas normalmente têm dificuldade de falar, mas isso vai se modificando à medida que elas vão percebendo o acolhimento e a reação das outras. V1 lembra que já ouviu outros pacientes contarem que pessoas disseram que não iam se sentar perto deles porque eles estavam com câncer. V4, em um

ix Essa última observação dificultou, por exemplo, o processo de transcrição da gravação, que captou esporadicamente falas desencontradas e perdidas. 
depoimento cômico e irônico, conta que sua prima trocou o número de celular, porque achou que ia pegar a doença pelas ondas do sinal do telefone.

Possivelmente, as meninas do Grupo Vitoriosas têm uma disposição maior para enfrentar a doença. O compartilhamento das experiências e o apoio oferecido pelo hospital possibilitam desnudar o câncer de seus mitos, e isso parece favorecer a forma com que essas pacientes lidam com a neoplasia. Elas procuram reproduzir isso, porque julgam que pode ser útil para outras pessoas; porém, os estigmas em outros espaços e circunstâncias podem ser mais resistentes.

Essa ideia pode ser verificada na fala de $\mathrm{V} 4$, ao abordar a sua visão antes e depois da doença:

"antes, era como a minha mãe falava: 'aquela doença', 'aquela doença'. Aí a gente tinha aquele medo. Aí quando eu fiquei sabendo que 'aquela doença' estava comigo, eu levei aquele choque assim e depois passou. Eu nem falava 'aquela doença' mais não, eu falava 'câncer', normal” (V4, 2015).

V6 (2015) assume que tinha muito medo de desenvolver câncer de intestino, porque o pai teve e, naquele momento, não sabia de nada, mas ficou sabendo que podia ser hereditário.

Indagamos, depois, sobre o fato de elas terem afirmado, quando do convite para participação em matérias de TV, que o câncer também tem coisas boas e que era preciso mostrar isso. Antes de completar a pergunta, V4 interrompe e, com empolgação, diz: "já apareci no Globo Esporte” (V4, 2015). Na continuidade, V2 fala que elas ganham muita qualidade de vida e enumera as atividades que lhes garantem essa qualidade: exercício físico, hidroginástica, alongamento, drenagem linfática, caminhada, artesanato e dança do ventre. Nesse momento, ela aproveita para ensinar as demais que não se deve falar "meu câncer", mas "o câncer". Isso parece, para ela, fazer toda diferença (V2, 2015).

Nessa hora, perguntamos se elas achavam que a mídia dava visibilidade às "coisas boas" de que elas tanto falam. Há um consenso de que isso está começando a acontecer. V6 ilustra com a ideia de que já é possível encontrar, por exemplo, matérias sobre maquiagem, sobre como usar uma echarpe, lenços etc. V2 contou da participação de V4 no Globo Esporte, por ocasião de uma corrida; a segunda já teria sido, inclusive, reconhecida na rua depois do programa. Elas falam disso com certo orgulho e vaidade. V1 conta que os corredores e os organizadores dão instruções: "olha, levanta a cabeça, não anda de cabeça baixa" (V1, 2015), e elas participam "por nossa livre e espontânea responsabilidade e vontade" (V1, 2015). V2 causa risadas ao contar: "tem gente que fala assim: 'essa corrida não é para vocês'. E a gente vai” (V2, 2015).

V1 considera que, aos poucos, elas estão conquistando espaço na sociedade. Nos momentos de baixa autoestima e de risco de depressão, as medalhas e os troféus são símbolos de capacidade, superação e vitória. Aos poucos também, a mídia já as acompanha nesse sentido. No que diz respeito à importância da informação para o tratamento, V6 é a mais efusiva ao comentar que procura informações na internet, com os médicos e com os demais profissionais. Ela acha que qualquer informação é importante e não concorda com o chavão de que "ignorar é um privilégio".

Nesse ínterim, V2 conta que, após fazer uma mamografia no ano passado, ela teria feito uma pesquisa na internet sobre o diagnóstico. Depois disso teria ficado desesperada porque entendeu que estava com câncer novamente. Ela marcou a consulta com a médica e chegou ao consultório apavorada. Porém, a médica teria dito que a consulta com o "Dr. Google" teria provocado desespero desnecessário, porque o exame não indicava a existência de um novo tumor. Desde então, afirma: "nunca mais eu mexo na internet para poder ver nada sobre câncer".

Ampla concordância existe no grupo a respeito da importância de os pacientes serem ouvidos e entrevistados em produtos jornalísticos. V4 acha que é importante "até para ajudar as pessoas que ficam depressivas. Têm umas que sabem da resposta e não saem nem de casa mais" (V4, 2015). V2 defende que é bom para "abrir os olhos" de outras pessoas, para elas prestarem atenção. V1 pensa que isso pode ajudar outras pessoas a também vencerem o câncer. Na oportunidade, V2 descreve outra situação vivida por ela, 
que também a deixou revoltada. À época do "Outubro Rosa”, elas fazem um trabalho de conscientização em diversos lugares. Porém, muitas pessoas as rejeitam, não dão atenção e jogam fora os panfletos por elas distribuídos. Essa situação a deixa consternada.

Após esse preâmbulo sobre a informação acerca do câncer, exibimos o vídeo veiculado pelo programa Bem-estar $^{\mathrm{x}}$ no dia 29 de outubro de 2014, que teve como personagem principal a participante V1. O VT foi ao ar 27 dias depois da gravação na Ascomcer. O conteúdo, com cerca de dois minutos, aborda basicamente a história dessa participante e de parte do Grupo Vitoriosas, explorando o interesse humano e a sensibilização. A veiculação do vídeo no grupo de discussão tinha o objetivo de relembrar o evento para que as interpelássemos sobre a representação realizada no âmbito televisivo. Todas elas se disseram bem representadas e $\mathrm{V} 4$ já dispara seu argumento:

"tem que tirar essa coisa da cabeça do pessoal, esse preconceito que eles têm da gente. Você entrar no ônibus e já arreda todo mundo. É uma coisa estranha. Aí, fazendo umas reportagens, vai tirando, né? A pessoa vai associando. Porque antes era a Aids [...]” (V4, 2015).

V1 e V4 declaram que é preciso eliminar os mitos da doença. V1 reforça a ideia de que matérias dessa natureza servem para dar esperança para outras mulheres, para que possam transformá-las assim como ocorreu com ela, porque isso não pode ser imposto. V6 completa que o câncer antes era escondido e, por isso, a mídia ajuda nesse sentido - "as pessoas que tinham na família escondiam dos outros" (V6, 2015) - porque atrai outros olhares e até voluntários para ajudá-las. Habituadas com um modelo noticioso consolidado e em um espaço de abrangência nacional, as pacientes parecem não atentar para as limitações estruturais da televisão, seus sentidos e significados, nem para seus elementos construcionistas, como ficou evidente durante a gravação no hospital - até mesmo pela generalizada falta de alfabetização para leitura crítica dos meios. A possibilidade de visibilidade e o próprio orgulho de ver sua identidade publicizada na TV aberta parecem prevalecer acima de qualquer outro eventual problema de cobertura ou representação. A realização desse próprio grupo de discussão é um forte exemplo de quantos e variados aspectos são silenciados pela mídia.

O discurso da esperança que tanto caracteriza a cobertura televisiva é visto, pelo senso comum, como algo positivo para elas. O debate se volta para o grupo quando V6 e V1 valorizam o apoio das profissionais, que foram importantes até para que ele seja hoje um grupo mais autônomo ou independente, pois propõe e realiza atividades fora do hospital por conta própria - o que não acontecia no início, como a psicóloga confirma.

\section{Considerações finais}

[...] o câncer será parcialmente desmitificado e, então, poder-se-á comparar alguma coisa com o câncer sem que isso implique um diagnóstico fatalista ou um excessivo apelo à luta por todos os meios contra tudo o que seja um inimigo mortífero e insidioso [...] a metáfora do câncer se tornará obsoleta - eu ousaria vaticinar - muito antes que os problemas por ela refletidos de modo tão persuasivo tenham sido resolvidos ${ }^{1}$.

Embora tenhamos abordado um grupo que lida com a doença de uma maneira mais autônoma ou livre de certos mitos, as vivências por elas descritas materializam amplamente os sentidos que o câncer ainda mobiliza na sociedade. Porém, chamaram-nos atenção fortemente os depoimentos e os casos que colocam esse público em condição de certa exclusão ou marginalização social, simplesmente por terem desenvolvido uma doença de caráter crônico, não epidêmico e não contagioso. Essa questão aponta para a real necessidade de se fazer ouvir suas vozes aberta e abrangentemente e, nesse sentido, o jornalismo tem um importante papel que não pode se restringir à simples ação de contar seus casos e dramatizá-los, como se faz em ficção. Falamos, portanto, de debates, aprofundamentos, dar visibilidade a ingerências e a demandas que, na prática, caracterizam o

x "Maria do Carmo usa arte para inspirar mulheres que enfrentam o câncer de mama" está disponível em: http://globotv.globo. com/rede-globo/bem-estar/v/maria-do-carmo-usa-arte-para-inspirar-mulheres-que-enfrentam-o-cancer-de-mama/3728410/ Acesso em 28 jan. 15. 
sistema. O preconceito relacionado ao câncer é, desse modo, um dos grandes desafios a ser inserido na agenda pública, a fim de combatê-lo. Esses problemas sociais, pouco problematizados pela mídia, possivelmente acentuam a dificuldade dos pacientes em aceitar a doença, sem querer fugir ou esconder. Ademais, a luta contra o câncer não parece ser travada somente no organismo, mas também no âmbito social e moral, para além de mecanismos medicamentosos ou terapêuticos disponibilizados pelas instituições de saúde.

É razoável considerar que a informação tem posição central nas questões de saúde pública. O conhecimento do próprio corpo, das mazelas que podem surgir, dos direitos que lhe competem nessa seara, das escolhas possíveis de serem feitas livremente podem determinar, para os indivíduos, uma série de relações simbólicas que estabelecem uma hierarquia do corpo social. Tendo em vista a preocupação das ferramentas comunicativas para a promoção da saúde, além de outras questões mais complexas, percebemos que também no caso do câncer a informação está no meio do campo de batalhas para que este se torne mais aceitável, ou menos estigmatizado pela população. E, sendo produtos de nossa cultura, notícias e reportagens tentam abordar esses mitos, às vezes por sua desconstrução e, em outros momentos, mantendo-os, ainda que de maneira indireta.

Uma ideia de suma importância na relação de trocas linguísticas está direcionada para aquilo que é silenciado, aquela informação que se quer esconder, independentemente de quem seja o interesse; é possível inferir que a saúde mobiliza questões de poder. Porém, o ato deliberado ou não de esconder ou de interditar determinados temas faz com que a informação permaneça restrita a determinados grupos privilegiados e, com isso, que uma maioria se veja dependente e sujeita ao autoritarismo daquele que detém o conhecimento. $\mathrm{O}$ silenciamento também, especialmente em relação às questões oncológicas, leva ao preconceito e à discriminação, o que potencializa, em alto grau, a dor e o sofrimento de estar com uma degenerescência física.

Por não ser conhecida a causa do câncer, há muita especulação na própria mídia, que ventila incertezas e possibilidades, dando abertura para mitos como os de que os tumores se desenvolvem em função de problemas morais ou emocionais, por um trauma, pela falta de atenção, pelo ressentimento ou pela mágoa. O câncer assume, portanto, para além de todos os outros dilemas que lhe são característicos, um efeito moralizante, que vem logo depois do diagnóstico, com o término do tratamento ou pelo seu estadiamento.

É quase impossível não associar a questão da informação com o acontecimento histórico de um século atrás, quando, fruto do desconhecimento e da desinformação, a população carioca se recusava a tomar a vacina contra a varíola,. Na atualidade, ainda existem aquelas pessoas que não vão ao médico, recusam-se até a receber informações sobre "aquela doença ruim", porque têm medo de "pegar". Aliás, também ainda vige a noção de que câncer é contagioso, e talvez por isso há algum tempo as famílias o escondiam. Hoje ainda, há famílias que escondem do paciente que ele está com câncer, por medo de que, ao saber, ele venha a morrer.

Essas condutas abrem precedentes para que pacientes sejam discriminados, marginalizados e excluídos, como se pôde verificar no grupo de discussão. Essa questão também nos coloca em posição confortável para defender a ideia de que é preciso falar mais sobre câncer, é preciso incluir na agenda, extirpar velhos mitos; mas, mais do que falar, também é imperioso ouvir, estabelecer diálogos com pluralidade de vozes, a fim de evitar reducionismos exacerbados, informações dissonantes e descontextualizadas e discursos ruidosos ou não comunicantes, sobretudo por conta de erudições dos operadores linguísticos.

Especialmente na relação desses atores sociais com a mídia televisiva, verificamos que a última insiste em construir narrativas marcadas pela 'mesmice', isto é, se vale de velhos símbolos e de uma concepção presumida de quais são os problemas vivenciados por essas mulheres. Os elementos da tessitura jornalística, explorados em áudio e vídeo, são montados para dar conta de todos os estereótipos consolidados da doença e de seus doentes, em detrimento de novas problematizações tangenciais, direitos e, de um modo geral, sem permitir que esse público tenha espaço para falar de algo que vá além do senso comum. A TV deixa evidente, pela observação da fase de apuração e pelo produto final, a capacidade de explorar a sensibilidade pela composição visual e sonora, estabelecendo um relato ficcional - pela dramatização e pela forma de composição -, com 
uma "carcaça" de verossimilhança. Cabe salientar o modo de condução das atitudes dos personagens e a presença dos depoimentos emocionantes em close-up.

\section{Referências}

1. Sontag S. A doença como metáfora. Rio de Janeiro: Graal; 1984. p. 7-9; p. 107-108.

2. Moraes NA. Comunicação e saúde: entre sentidos, interesses e estratégias. ECO-PÓS - publicação da pós-graduação em comunicação e cultura. jul 2007; 10(1):64-78.

3. Moura DO. Comunicação em saúde: apenas remediar ou participar e prevenir? In: Mendonça V et. Al organizadores. Comunicação da informação em saúde: aspectos de qualidade. Brasília: Editora do Departamento de Ciência da Informação e Documentação (UnB); 2008.

4. Araújo I, Cardoso J. Comunicação e saúde. Rio de Janeiro: Editora Fiocruz; 2007. p. 87.

5. Traquina N organizador. Jornalismo: questões, teorias e "estórias". Lisboa: Veja; 1993. p. 168.

6. Goffman E. A representação do eu na vida cotidiana. Petrópolis: Vozes; 1985.

7. Berger $P$, Luckmann T. A construção social da realidade: tratado de sociologia do conhecimento. Petrópolis: Vozes; 1985.

8. Berger P, Luckmann T. Modernidade, pluralismo e crise de sentido: a orientação do homem moderno. Petrópolis: Vozes; 2004. p. 68.

9. Alsina MR. A construção da notícia. Petrópolis: Vozes; 2009. p. 229.

10. Ribeiro AP, Sacramento IP. Mikhail Bakhtin e os estudos da comunicação. In: Mikhail Bakhtin: linguagem, cultura e mídia. São Carlos: Pedro e João Editores; 2010. p. 28.

11. Wolton D. Elogio do grande público - uma teoria crítica da televisão. São Paulo: Ática; 1996. 